\title{
ANÁLISE DAS MANIFESTAÇÕES PATOLÓGICAS NA ESTAÇÃO DE TRATAMENTO DE ÁGUA DE JURU-PB
}

\author{
SOUZA, VITORIA B. \\ Estudante \\ IFPB-PI \\ Paraíba; Brasil \\ barbosadesousavitoria@gmail.com \\ RAMOS, MARIA A. \\ Estudante \\ IFPB-PI \\ Paraíba; Brasil \\ maria.ayslanne@gmail.com
}

\author{
LEITE, LAIANY K. F. \\ Estudante \\ IFPB-PI \\ Paraíba; Brasil \\ laianykeilla15@gmail.com \\ SOUSA, NÍLBERTE M. \\ Professor \\ IFPB-PI \\ Paraíba; Brasil \\ niberte.muniz@hotmail.com
}

\section{RESUMO}

As estruturas utilizadas para receber, armazenar e tratar as águas nas estações de tratamento, em sua grande maioria, são de concreto, sobretudo os tanques. Estes estão constantemente em contato com a água e produtos químicos utilizados durante o tratamento. Além disso, existem as exposições tanto a intempéries quanto, a temperaturas que apresentam grande variação entre dia e noite, como é percebido na Região da Serra de Teixeira, no sertão paraibano. Todos esses fatores contribuem para o surgimento de danos às estruturas de concreto. Diante disso, o presente trabalho objetiva examinar e verificar as patologias existentes nas estruturas de concreto armado na estação de tratamento de água localizada em Juru-PB. Com isso, adotou-se como metodologia a inspeção visual, realização de medições in loco com a ultilização de instrumentos de medições e registros fotográficos para uma analise detalhada. Diante das investigações foi possível perceber a existência de diversas manifestações patológicas, que estão quase sempre relacionadas às falhas executivas e a deficiência no sistema de manutenção periódica e que, gradativamente, reduz a vida útil dessas estruturas.

Palavras-chave: estação de tratamento de água, estrutura, manifestações patológicas.

\begin{abstract}
The structures to receiving, storing and treating water in the treatment plant, on its great majority, are with concrete, especially the tanks. These are constantly in contact with the water and chemical products used during the treatment. Furthermore, there are exposures to elements as much as temperatures which shows variation between day and night, as perceived in the Teixeira Mountain Range region of the northeastern Brazilian state of Paraíba. All these factors contribute to the damage development in the concrete structures. In view of that, the aim of this work objectives examine and verify the pathologies on the reinforced concrete structures in the water treatment plant localized in JuruPB. Thus, was adopted as methodology the visual inspection, achievements of measurement in loco use of measuring instruments, and photographic registers for a detailed analysis. Face of the investigations was possible notice the existence of diverse pathologic manifestations, which are almost always related to executive failures and deficiency in the periodic, and gradually reducing the useful life of these structures.
\end{abstract}

Keywords: water treatment plant, structure, pathological manifestations. 


\section{INTRODUÇÃO}

O desenvolvimento da vida humana depende da disponibilidade de recursos de água doce. Muitos países têm recursos abundantes em água potável, enquanto outros têm recursos limitados (BOUROUNI, 2013). Assim, a água potável é uma grande preocupação em países em desenvolvimento e com escassez de água, a exemplo da região nordeste no Brasil. Onde o rápido crescimento populacional, industrialização extensiva e atividades agrícolas resultaram na poluição das fontes de água (TSHINDANE et. al., 2019).

Com isso, surge a necessidade de fornecer serviços essenciais como a produção e o fornecimento de água potável através das estações de tratamento e redes de infraestrutura localizadas em áreas urbanas e rurais. Assim, é fácil perceber a importância das Estações de Tratamento de Água (ETA), principalmente no sertão Paraibano, onde os habitantes dessa região estão frequentemente em contato com a escassez de água potável.

De acordo com Smit et. al. (2019) as estações de tratamento de água ETAs formam uma parte essencial dos sistemas de água potável e podem ser caracterizadas por três particularidades: (I) são sistemas complexos que consistem em uma infinidade de componentes; (II) seus componentes sofrem deterioração, ou seja, seu desempenho diminui devido ao envelhecimento; (III) ETAs são sistemas reparáveis, ou seja, dada a falha de alguns componentes, eles podem continuar operando sem um desligamento e substituição completa do sistema. Ainda conforme, Smit et al.(2019), esses ativos têm uma vida útil longa, geralmente acima de 50 anos.

Entretanto, a negligência na conservação e até mesmo a falta de manutenção nas estruturas das Estações de Tratamento, acarretam no surgimento das manifestações patológicas que trazem diversos prejuízos, entre eles podemos destacar o desperdício da água e o interropimento do abastecimento de água potável.

Segundo Sousa et. al. (2015), a estações de tratamento de água são construídas, em sua grande maioria, com a utilização do concreto, sobretudo os tanques que recebem, armazenam e conduzem a água durante todo o tratamento. Por estes tanques se encontrarem em contato constante com água e expostos a intempéries como também a variação de temperatura durante o dia e a noite, além de substâncias usadas no tratamento, que podem ocasionar danos ao concreto, resultando na redução da sua vida útil.

As patologias das construções podem ser entendidas, analogicamente à ciência médica, como o ramo da engenharia que estuda os sintomas, formais de manifestação, origem e causa das doenças ou defeitos nas edificações (CARRARO, 2010). Já para Ferreira e Lobão (2018), as principais causas de patologias são as deficiências de projeto, deficiências de execução, má qualidade dos materiais ou emprego inadequado dos mesmos, uso inadequado da estrutura e manutenção imprópria ou até mesmo a falta da mesma.

De acordo com Neumann et. al. (2019), as patologias são pequenos defeitos que aparecem geralmente alguns meses ou anos depois que a edificação é concluída, essas manifestações são classificadas como fissuras, trincas, corrosão, manchas de umidade, descolamentos, deformação e rupturas.

A corrosão é uma interação destrutiva de um material com o ambiente, seja por reação química, ou eletroquímica. Também é definida como a deterioração dos materiais pela ação química ou eletroquímica do meio, podendo estar ou não associada a esforços mecânicos (SANTOS; VITÓRIO, 2016).

Conforme Oliveira (2012), as fissuras e trincas são manifestações patológicas das edificações observadas em alvenarias, vigas, pilares, lajes, pisos entre outros elementos, geralmente causadas por tensões dos materiais. Se os materiais forem solicitados com um esforço maior que sua resistência, acontece a falha provocando uma abertura, e conforme sua espessura será classificada como: fissura, trinca, rachadura, e ou brecha.

As manchas de umidade, são marcas escuras ocasionadas pela ascensão da água à superfície, seja por capilaridade ou por fenômenos externos, como chuvas. A água pode, em um possível agravamento, atingir a armadura e estimular o surgimento de corrosão e outras manifestações patológicas (LOPES et al., 2018).

Segundo Souza e Ripper (1998), a desagregação do material é um fenômeno causado por muitos fatores, ocorrendo, na maioria dos casos, em conjunto com a fissuração. Devendo-se entender como desagregação, a separação física de placas de concreto, com perda de monolitismo, da capacidade de acomodação entre os agregados e da função ligante do cimento. 
Uma peça com seção comprometida mediante desagregação do concreto, perde localizada ou globalmente, a capacidade de resistir aos esforços aos quais está submetida.

A temperatura também é um fator que contribui bastante para a danificação do concreto. De acordo com Costa (2011), o aumento da temperatura nos elementos de concreto provoca redução no módulo de elasticidade e na resistência características de seus materiais constituintes, havendo prejuízos na rigidez do elemento.

Sendo assim, este trabalho tem por finalidade analisar as manifestações patologias encontradas na estação de tratamento de água situadas no município de Juru-PB, Região da Serra de Teixeira, no sertão Paraibano, com o intuito de verificar o desgaste das estruturas.

\section{METODOLOGIA}

A metodologia adotada foi uma pesquisa in loco, na Estação de Tratamento de Água (ETA) na cidade de Juru-PB, onde foi realizada uma análise visual da incidência de patologias presentes no ambiente, cujas ferramentas utilizadas foram o registro fotográfico para posterior análise e avaliação geral do estado de conservação da estrutura e instrumentos de medições, tais como trenas e paquimetros.

\section{RESULTADOS E DISCUSSÃO}

\subsection{Corrosão das armaduras e oxidação de tubulações}

Nos tanques de armazenamento de água tratada foi possível observar a presença de fissuras, e consequentemente, essas permitiram a infiltração de água nas estruturas, o que resulta na corrosão das armaduras. O mecanismo de corrosão do aço no concreto é eletroquímico, tal qual a maioria das reações corrosivas em presença de água ou ambiente úmido. Esta corrosão conduz à formação de óxidos/hidróxidos de ferro, produtos de corrosão avermelhados, pulverulentos e porosos, denominada ferrugem, como mostrado na (Figura 1), reduzindo assim, drasticamente a vida útil da estrutura.

Há muito tempo, os sistemas de tubulações de metal têm sido a escolha padrão de engenheiros e arquitetos em aplicações industriais, devido à sua resistência e durabilidade em ambientes de alta temperatura e pressão. Entretanto, em ambientes que possuem contato constante com a umidade e até mesmo com a água, necessita-se de cuidados específicos para garantir a durabilidade desses materiais.

Na Estação de Tratamento de Agua ETA em estudo, foi observada a presença de tubulações oxidadas decorrente do constante contato com a água e a falta de manutenção nesse sistema (Figura 2), o que leva a um grande dano da estrutura uma vez que, a oxidação reduz à resistência das tubulações e as pressões a que são submetidas.

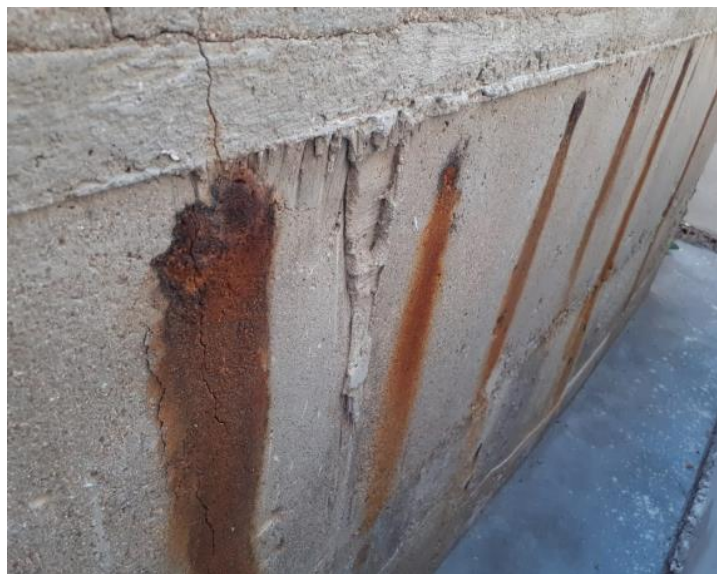

Figura 1: Início da corrosão do aço

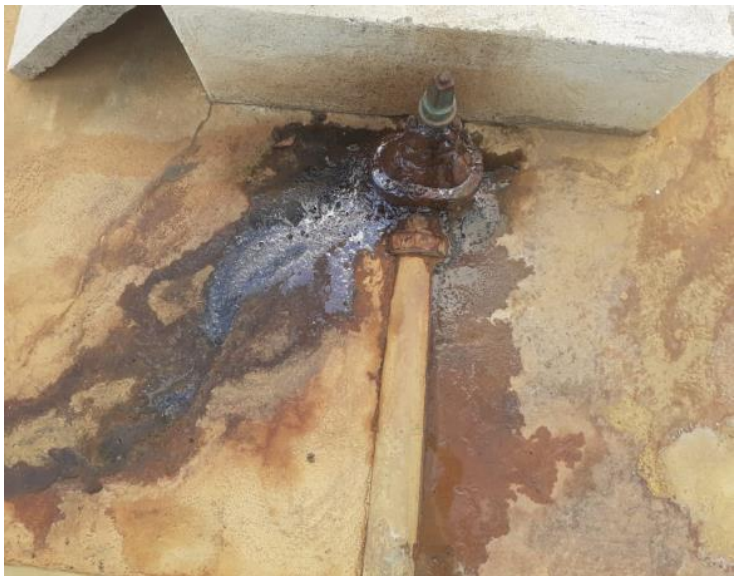

Figura 2: Oxidação da tubulação e manchas de umidade 


\subsection{Fissuras e trincas}

As fissuras existentes nas estruturas da estação de tratamento de água podem ter diferentes origens, como a composição do traço utilizado para executar a estrutura, a baixa resistência à tração sob as ações de serviço e utilização, por retração térmica e no processo de cura (SOUSA et. al., 2015). E quando a estrutura não tem a manutenção devida pode acarretar muitos problemas, e levar até ao colapso da edificação.

Na ETA estudada, foi possível observar fissuras e trincas nos tanques de armazenamento de água (Figura 3), o que possibilita infiltrações e consequentemente servir como facilitador para o surgimento de diversas manifestações patológicas como o bolor, segundo Cincotto (1988), é caracterizado por manchas esverdeadas ou escuras que tem como possível causa à presença de umidade constante ou por revestimento em desagregação (Figura 4). Esse tipo de patologia também foi identificada em grande parte do piso da estrutra (figura 5), inclusive, com presença de recalque em alguns pontos (Figura 6).

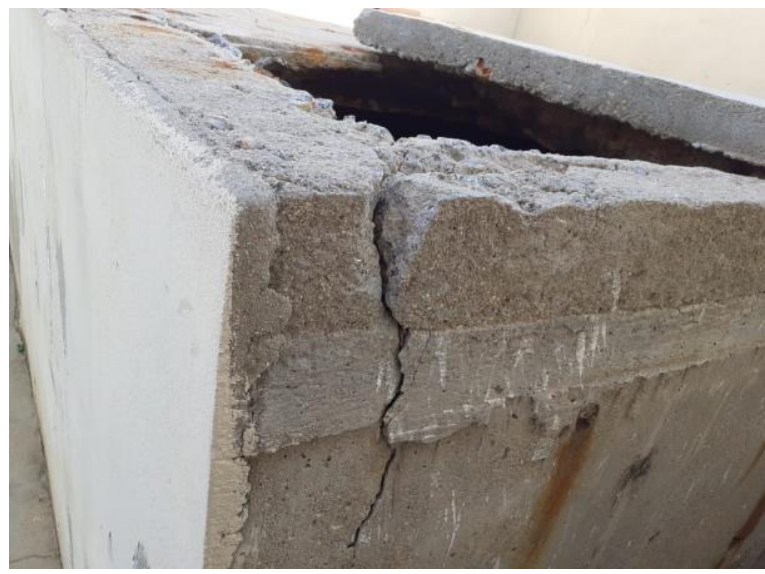

Figura 3: Trinca no tanque de armazenamento de água

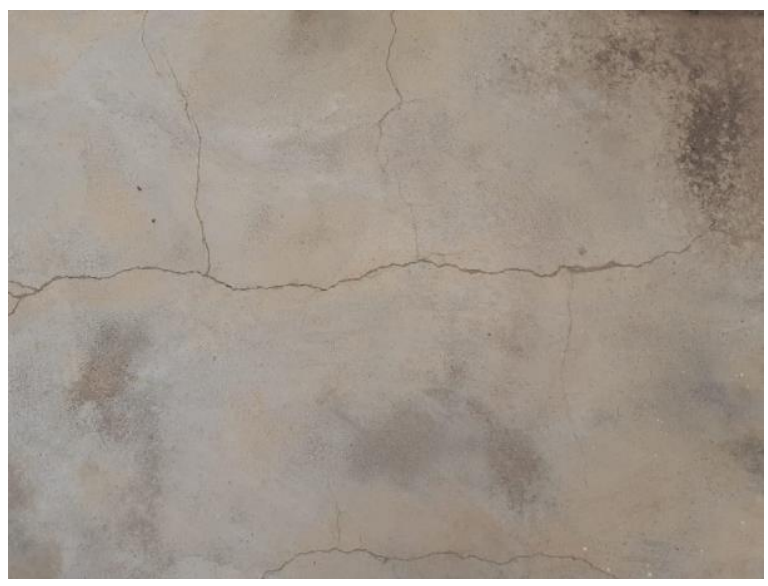

Figura 5: Trincas no piso da ETA

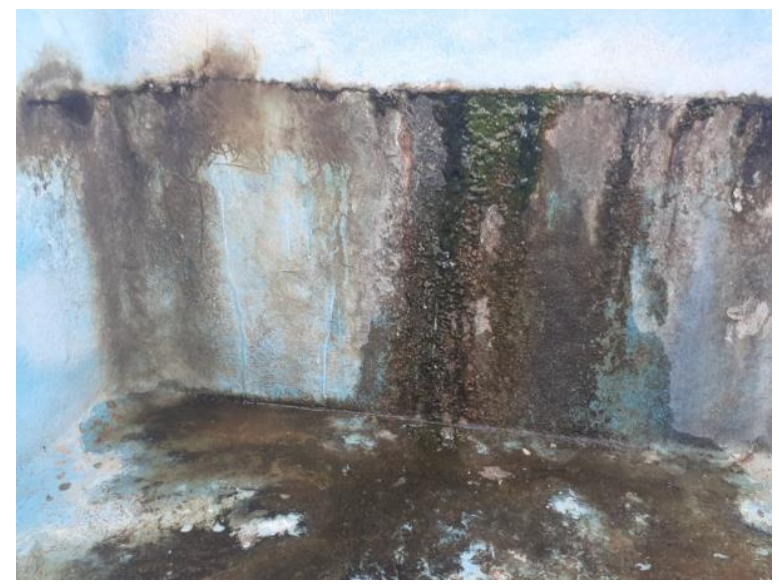

Figura 4: Infiltração na fissura e surgimento de mofo e bolor

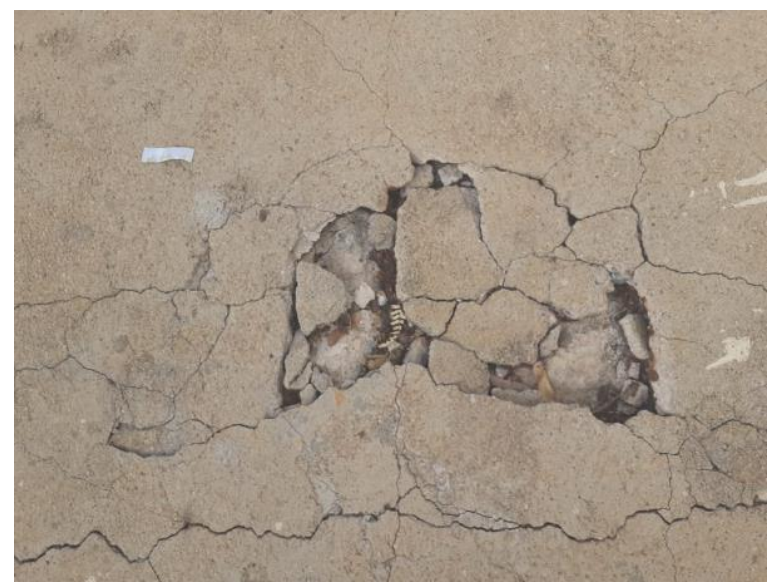

Figura 6: Tincas e fissuras no piso recalcado

\subsection{Degradação do concreto}

De acordo com Souza e Ripper (1998), a degradação do concreto se dá devido a muitos fatores, na ETA em estudo ocorreu em consequência do movimento das águas nos tanques de armazenamento de água e provavelmente intensificado pelos produtos químicos a exemplo o cloro e o sulfato de ferro, usados no processo de purificação da água. 
Foi possível perceber a degradação do concreto nos tanques de armazenamento (Figura 7). Podendo ainda, notar que em alguns pontos dos tanques os desgastes já não eram mais superficiais, apresentando certa gravidade.

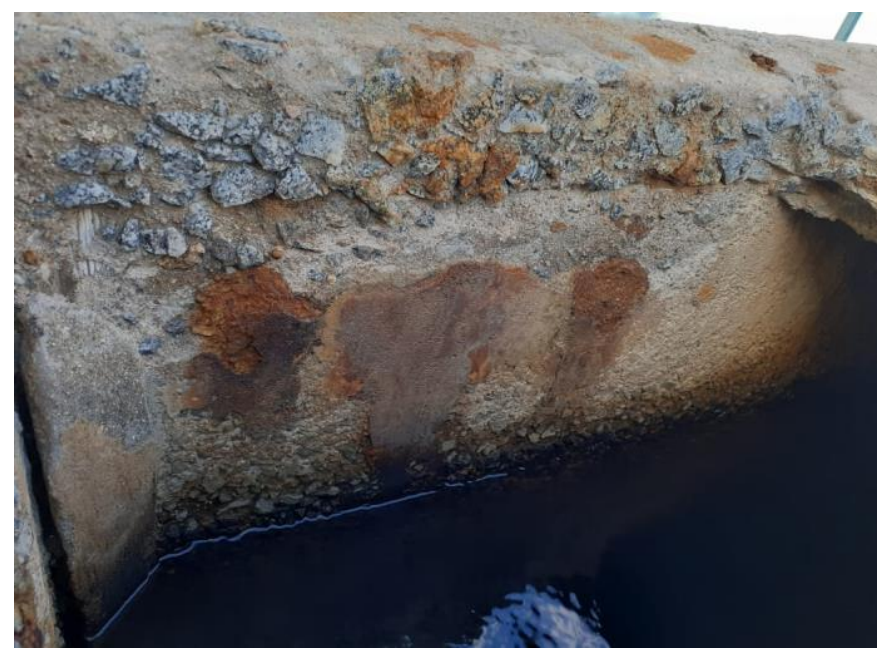

Figura 7: Degradação do concreto no tanque de armazenamento

\subsection{Manchas de umidade}

Nas instalações da ETA foi observada uma grande quantidade de manchas de umidade, principalmente nas bases das bombas e motores (Figura 8), oriundas provavelmente de vazamentos existentes nas próprias bombas ou nas tubulações acoplados a esses equipamentos. Nas bases dos reservatórios, tanto superiores (Figura 9) quanto inferiores, também foi observada a existência das manchas de umidades, decorrentes do escape de água e também a má impermeabilização da laje o que permite que a água passe pelas brechas e chegue então à estrutura de concreto.

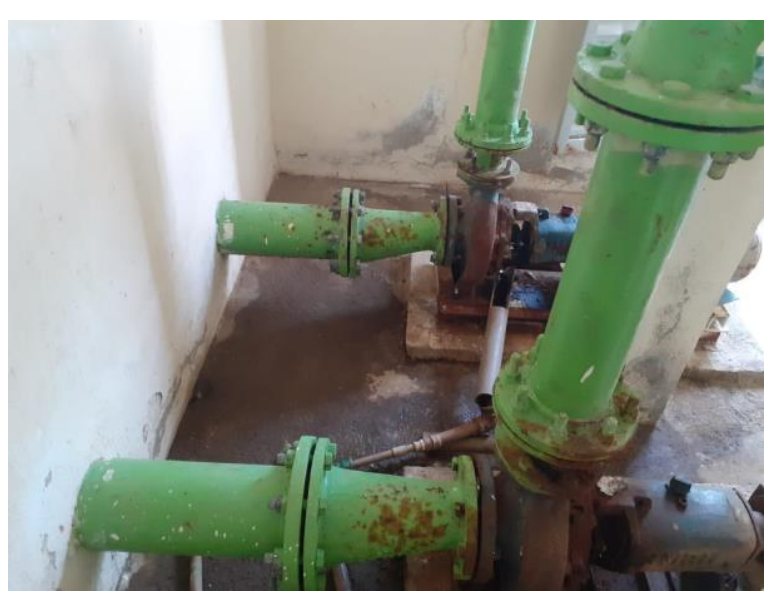

Figura 8: Manchas de umidade na base das bombas

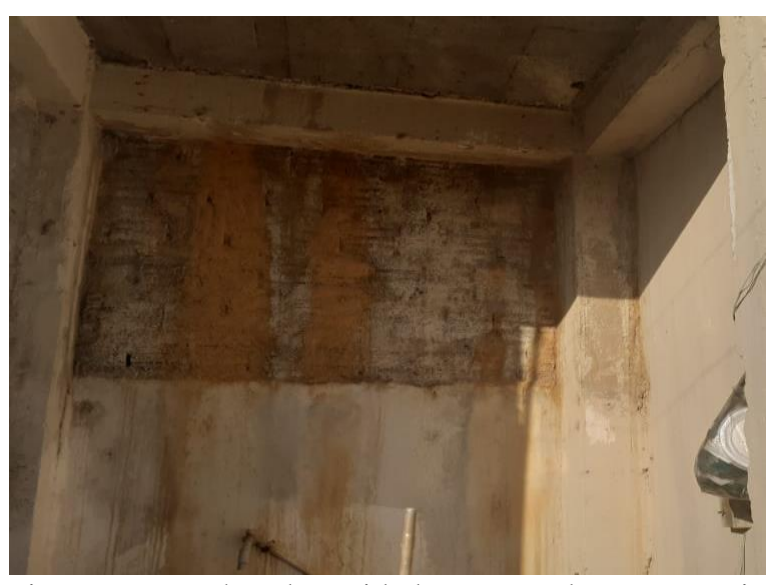

Figura 9: Manchas de umidade na pase do reservatorio superior

\section{CONCLUSÕES}

Através das análises realizadas, foi possivel identificar que em todos os ambientes da Estação de Tratamento de Água da cidade de Juru - PB foram detectadas presença de diversas manifestações patológicas, algumas delas em um estado avançado e outras mais moderadas. Após as observações, conclui-se que o surgimento das patologias podem se originar 
de diversas formas, e sem a manutenção para fazer a estabilização dessas podem vir a surgir novas manifestações o que levaria tanto a um desgaste maior da estrutura quanto à redução mais acelerada da sua vida útil.

Isso mostra que por se tratar de uma instalação pública, existe um certo descaso com a sua conservação. Com a inexistência da manutenção preventiva, como também a falta da manutenção corretiva que visa recuperar as falhas identificadas o quanto antes, para que as mesmas não venha a prejudicar ainda mais a edificação no futuro, o que acarreta, pelo estado encontrado na ETA, altos custos para reparo ou recuperação.

As estruturas da ETA estudada necessitam de uma intervenção o quanto antes, para que possam ser realizadas atividades de recuperação e assim, evitar o seu colapso, visto que, o agravamento dessas manifestações levaria a um elevado desperdício de água, o que traria consigo problemas para a população. Uma vez, que esta é a única fonte que possibilita o fornecimento de água potável para a população da cidade onde fica situada, e este seria um dano coletivo.

\section{REFERÊNCIAS}

BOUROUNI, K. Availability assessment of a reverse osmosis plant: Comparison between Reliability Block Diagram and Fault Tree Analysis Methods. Desalination. V. 313, p. 66-76, 2013.

CARRARO, C. L. Análise pós-obra de habitação de interesse social visando a identificação de manifestações patológicas. 2010. 155 f. Dissertação (Mestrado) - Universidade Federal de Uberlândia. Uberlândia, MG, Brasil, 2010.

COSTA, P. R. S. Manifestações patológicas nas estruturas de concreto sujeitas a altas temperaturas. Monografia. Escola de Engenharia da Universidade Federal de Minas Gerais, Belo Horizonte, 2011.

CINCOTTO, M. A. Patologia das argamassas de revestimento: análise e recomendações. In: IPT - Instituto de Pesquisas Tecnológicas do estado de São Paulo. Tecnologia das Edificações. São Paulo: PINI, 1988.

Ferreira, J. B.; Lobão, V. W. N. Manifestações patológicas na construção civil. Ciências exatas e tecnológicas, v. 5, n.1, p. 71-80, 2018.

LOPES, M. A. M.; et al. Análise de manifestações patológicas em fachadas de edifícios residenciais da avenida Boa Viagem, em Recife-PE. In: Congresso Técnico Científico da Engenharia e da Agronomia. 2018. Anais... 2018.

NEUMANN, P. N.; et al. Patologias nas edificações: uma nova concepção na construção civil. Revista Interdisciplinar de Ensino, Pesquisa e Extensão, v. 4, nº 1, p. 315-326, 2016.

OLIVEIRA, A. M. Fissuras, trincas e rachaduras causadas por recalque diferencial de fundações. (Trabalho conclusão de curso). Curso de Especialização em Gestão em Avaliações e Perícias. Universidade Federal de Minas Gerais, Belo Horizonte, 96 p, 2012 .

SANTOS, D. C. P.; VITÓRIO, J. A. P. Um Estudo das Manifestações Patológicas e das Condições Estruturais da Ponte sobre o Rio Iga-rassu na BR 101/PE. Revista de Engenharia e Pesquisa Aplicada, v. 3, n. 1, 105-114, 2016

SMIT, R.; LOO, J. V.; BOOMEN, M. V. D.; KHAKZAD, N.; HECK, G. J. V.; WOLFERT, A. R. M. Long-term availability modelling of water treatment plants. Journal of Water Process Engineering. V. 28, p. 203-213, 2019.

SOUSA, N. M.; ROCHA, G. G.; DINIZ, Y. L.; RIBEIRO, I. J. C. Manifestações patológicas em concreto armado nas estruturas da estação de tratamento de águas na cidade de Monteiro - PB. In: $57^{\circ}$ Congresso Brasileiro do Concreto, 2015, Bonito - MS. Anais..., 2015.

SOUZA, V. C. M.; RIPPER, T. Patologia, Recuperação e Reforço de Estruturas de Concreto. São Paulo: PINI, 1998.

TSHINDANE, P.; et al. The occurrence of natural organic matter in South African water treatment plants. Journal of Water Process Engineering. V. 31, p. 1-7, 2019. 